\title{
LAS UNIDADES DE PLANIFICACIÓN Y GESTIÓN TERRITORIAL COMO DIRECTRIZ PARA LA ZONIFICACIÓN URBANA.
}

\author{
PLANNING UNITS AND LAND MANAGEMENT AS GUIDELINES FOR URBAN \\ ZONING.
}

Recibido: Enero 2014 Revisado: Marzo 2014 Aceptado: 1 de Mayo 2014

Por: Ernesto Villegas Rodriguez. ${ }^{1}$

\section{RESUMEN.}

El presente artículo, derivado de investigación, presenta el marco conceptual y metodológico resultados del estudio de las Unidades de Planificación Territorial y de Gestión como Instrumento Operativo para la toma de Decisiones Urbano Rural, los POTs y PDM, instrumentos de planteamiento en el corto, mediano y largo plazo, en este orden la zonificación del territorio se convierte en la alternativa para plantear y fortalecer las Unidades de Gestión y Planificación Territorial donde se debe fortalecer la institucionalidad a partir de la incorporación de los actores y sectores público, privado y sociedad civil.

\section{PALABRAS CLAVES.}

Unidades de Gestión; Desarrollo urbano, Ordenamiento territorial y políticas públicas.

\section{ABSTRACT.}

This current article, derived from a piece of research, introduces in the theoretical and methodological frameworks, the results of a study of the Land Planning Units and of Management as an Operational Instrument for the Rural-Urban decisionmaking, the Territorial Ordering Plan -TOP- and Municipal Development Plan MDP-, instruments of approach in the short, medium and long terms; in this order, the zoning of the territory becomes an alternative to raise and to strengthen the Management Units and the Territorial Planning, where the institutional framework must be consolidated from the incorporation of public, private actors and sectors, and the civil society.

\section{KEY WORDS.}

Management Units; Urban Development; Territorial Ordering, and Public Policies.

${ }^{1}$ Grupo de Investigación Territorio y Habitabilidad, Docente investigador Universidad de América. Bogotá. Colombia. Contacto: villegas@profesores.uamerica.edu.co 


\section{Introducción.}

En los últimos tiempos hemos modificado el nivel de intervención territorial en términos de gestión administrativa y desarrollo territorial, se le han venido dando varios esquemas de organización al territorio dependiendo de las condiciones básicas de intervención territorial a través de directrices de planes de desarrollo posicionando en sus decisiones organizaciones de gestión desde los ambiental, social, económico y administrativo, olvidándose de alguna manera la reflexión integral en las disposiciones en la viabilidad social, económica y ambiental.

En fin, el uso de Unidades también ha venido acompañadas de metodologías para su implementación algunas de ellas desde lo ambiental en temas de manejo de recursos hídricos como en la intervención de unidades de paisaje entre otros. Por lo tanto, este artículo como resultado de la investigación central cuyo objetivo tenia directamente incidencia en el diseño del modelo de asociación territorial a escala urbano rural, que integre estrategias de diseño urbano arquitectónico de equipamiento y espacio público, para generar núcleos de unidades asociativas socioeconómicas y ambientales de gestión, como instrumento operativo en los POT Y PDM"

Sin embargo, se evidenciaron que al intervenir el territorio por medio de unidades de gestión y de planificación se logró establecer la relación directa de un extenso marco legal que conlleva a la reflexión del abordaje y concreción del tema de posicionamiento administrativo de la región en Colombia, aportantes de elementos en la construcción del nuevo modelo. Entre los elementos que contribuyen se encontraron algunos principios rectores y ordenadores para la aplicación del modelo, como son las políticas públicas enmarcadas en el desarrollo territorial como es la puesta en marcha de la Ley 388 de 1997, su decreto reglamentario 3600 de 2007, el cual definió lineamientos para el ordenamiento rural promoviendo los cambios de los usos del suelo a través de la construcción de vivienda en suelos aptos agrológicamente para el desarrollo agropecuario.

Lo establecido por el Ideam y el Ministerio de Ambiente a través de la zonificación de la Estructura Ecológica Principal (Eep), como eje estructural del ordenamiento territorial complementa la armonización territorial en lo establecido por la reciente Ley Orgánica de Ordenamiento Territorial 1454 de 2011 la cual será el parámetro legal para afianzar la descentralización territorial con un modelo de gobierno local que facilite el cumplimiento de los fines esenciales del Estado entendiendo que lo ambiental constituye la decisión más armónica de intervenir territorialmente el ordenamiento. Algunas bases para la zonificación del territorio se pueden determinar teniendo en cuenta: 1. La división veredal; 2. La red vial actual y/o futura, de asentamientos existentes; 3. La Estructura Ecológica Principal como elemento ordenador; 4. La disposición de las actividades productivas; $\mathbf{5}$. La Cuencas Hidrográficas, cerros y planicies u otros elementos geográficos.

Además algunos análisis desde la caracterización, el régimen y uso del suelo a través de las actuales divisiones político-administrativas de los municipios, se ha buscado la caracterización de indicadores que midan las diferencias y desigualdades 
territoriales a través de las dimensiones del desarrollo; con dichas dimensiones se llegue a la zonificación del territorio en diferentes Unidades de Planificación y de Gestión en el territorio, donde se determinen los niveles de prevalencia en el desarrollo y crecimiento a través de la gestión de la Cuenca Hidrográfica en asocio de los lineamientos para la construcción de la incorporación Estructura Ecológica Principal, en diseños territoriales más sostenibles y proyectos urbanísticos y arquitectónico mejor concebidos, más equitativos y socialmente sostenibles con su entorno natural .

Finalmente, y como objetivo el artículo enfatizará en el proyecto territorial teniendo en cuenta las posibilidades de conformación urbanística buscando la visualización de las tendencias de desarrollo productivo como armonización en términos urbano -rural. Tendencias de crecimiento y desarrollo sometidas a los cambios en el uso y régimen del suelo por inversiones del sector público o privado, con impacto directos en la participación ciudadana la cual cada vez más activa en las condicione de viabilidad de los proyectos donde se involucran las bases de los mecanismos de participación como instrumento de planificación y de gestión territorial conocidos por las diferentes actuaciones de las normas hoy vigentes, lo cual se propone visualizarlo desde cada una de las Unidades de Gestión y de Planificación Territorial propositivas.

De esta manera, se sientan las bases para atender las necesidades insatisfechas de la población y para mejorar la calidad de vida de todos los ciudadanos. Por lo tanto, desde la definición de la Visión "Municipal Regional o Departamental", a través de conceptos como el Desarrollo Sostenible, con el fin de construir colectivamente una imagen futura del "territorio", lo cual, consiste en lo que pretendemos sea realizable al cumplir con los Planes de Desarrollo como de Ordenamiento Territorial y de Cuencas Hidrográficas; es decir las proposiciones de armonización deben ser claras y precisas referentes a las metas que se persiguen en el logro de los objetivo de los Pg, Pot, y Pomcas entre otros instrumentos de planificación apoyados en la formulación de los respectivos objetivos de desarrollo que se promulguen en distintas politicas públicas nacionales e internacionales que inciden totalmente en la concepción de desarrollo y crecimiento territorial y mejoramiento de la calidad de vida.

\section{Metodologia.}

La investigación que da origen al presente texto, se desarrolló dando importancia al reconocimiento del termino como "Unidad": la investigación se identificó con el título "La Unidad de Planificación Territorial y de Gestión, como Instrumento Operativo para la toma de decisiones urbano rural en los Pot y Pdm". Que definió el marco legal, con el cual, se reconoce en los distintos contextos internacionales nacionales y local la intervención de dicho concepto, que metodológicamente se han definido teniendo en cuenta variables sociales, económicas administrativas, territoriales y ambiental en la aplicación de sus políticas públicas.

La definición de "unidad" llevo a la conceptualización y la visión en el cual en distintos contextos de gobierno le han dado en su intervención enfoques que en el momento de planificas son determinantes solamente para lo que fueron constituidas, llevando 
siempre distanciamientos en el momento de las tomas de decisiones como puede ser en lo nacional en los megaproyectos de hidrocarburos o minería y si nos vamos a lo departamental en la caracterización de unidades ecológicas o de paisaje y en lo local se encuentran grandes debilidades por lo que administrativamente los municipios no logran institucionalmente independizarse de algunas politicas públicas que son promulgadas desde lo nacional pero que inciden directamente en el desarrollo territorial. Teniendo en cuenta las últimas decisiones como es la Ley Orgánica de Ordenamiento Territorial (Loot) la cual, según el artículo 288 "establecerá la distribución de competencias entre la nación y las entidades territoriales" (Ley 1454, 2011). Los Decretos para el desarrollo de los Pomcas, el municipio necesita de unidades de planificación mucho más dinámicas que logren armonizar administrativamente decisiones que lleven al municipio a la armonización de la región directamente en la puesta en marcha de los distintos Planes de Desarrollo y armonizar los Planes de Ordenamiento Territorial ya sea por medio de la Ley 388 de 1997; Ley 614/00 y por los decretos 1729/02 - 3600/07 - 1640/12 - 1454/12, lo cual, nos debe llevar a la construcción de un país mucho más viable desde lo político y administrativamente jurídicamente entendiendo que la construcción de la descentralización territorial se debe fortalecer desde abajo hacia arriba fortaleciendo la participación de sectores, gremios y sociedad civil. Para ello.

Algunos lineamientos de políticas públicas apuntan a procesos de descentralización territorial siempre y cuando lo veamos desde el desarrollo unitario y teniendo en cuenta el centralismo cuando decisiones ambientales se deben mirarse desde una óptica local y regional, donde acciones de justicia y participación deben diseñarse desde el fortalecimiento de capacidades y cooperación a incluir instrumentos regionales para el desarrollo de la legislación nacional sobre acceso a la información, participación pública y acceso a la justicia en materia ambiental; socialización de los talleres de La Declaración sobre la aplicación del principio 10 de la Declaración de Río sobre el Medio Ambiente y el Desarrollo de América Latina y el Caribe se firmó en el marco de la Conferencia de las Naciones Unidas sobre el Desarrollo Sostenible (Río+20), realizada en Río de Janeiro en junio de 2012. (Nogué, 2010) y

"El municipio como entidad territorial es fundamental en la división politico administrativa del Estado, con autonomia politica, fiscal y administrativa dentro de los limites que lo señalen la Constitución y la ley y cuya finalidad es el bienestar general y el mejoramiento de la calidad de vida de la población en su respectivo territorio". (Pochat, 2005) - La Ley estatutaria de los mecanismos de participación del pueblo regula la iniciativa popular legislativa y normativa; el referendo; la consulta popular, del orden nacional, departamental, distrital, municipal y local; la revocatoria del mandato; el plebiscito y el cabildo abierto. Establece las normas fundamentales por las que se regirá la participación democrática de las organizaciones civiles. (Nogué, 2010)

Las Unidades de Planificación en su conceptualización territorial se dan como elemento básico para conocer y caracterizar el sistema territorial sobre el que se debe actuar e intervenir en el desarrollo e implementación de las políticas públicas $\mathrm{y}$, a partir de ahí, definir la estructura sobre la que se va a proceder la intervención 
territorial. En las distintas representaciones conceptuales que se presentan en el territorio como uso de los instrumentos de planificación, son incluyentes todos aquellos elementos que caracterizan el medio físico en lo biótico y abiótico y su incidencia antrópica pero evitando la acumulación de datos innecesarios que pueden llevar a un sobreesfuerzo en las tomas de decisión por los distintos actores y sectores lo cual puede incidir en intervenciones improductivas. Para ello, se dará prioridad a algunos de los elementos sociales, ambientales, económicos y administrativos o a la interrelación o combinación de todos ellos.

Como se dijo anteriormente, en los distintos contextos de las distintas naciones, se han venido desarrollando aproximaciones y desarrollo al concepto de Unidades de Planificación Territorial, algunas de ellas, dándole énfasis al desarrollo productivo, otras al fortalecimiento político e institucional, como también al mejoramiento de la calidad ambiental de nuestros territorios, teniendo en cuenta las directrices para el ordenamiento y planificación territorial; las unidades identificadas en el proyecto se pudieron reconocer y estudiarlas y ver sus incidencias en la aplicabilidad especialmente en tres instrumentos de planificación tales como Pdn, Pdd, Pdm, Pot y Pomcas. Algunas unidades fueron identificadas en el caso para Colombia en el manejo de los resultados de negociaciones de Paz en al Habana Cuba, las denominadas Unidades Administrativas Especiales para la Consolidación Territorial. (Uaect).

El presente artículo, por lo tanto, reconoce a algunas unidades como estrategias para la consolidación de políticas públicas e innovación de compromisos globales en las naciones especialmente en América-Latina y el Caribe que se han comprometido a impulsarlas desde visiones ambientales, sociales y económicas específicas; pero que a través de los Planes de Desarrollo y Planes de Ordenamiento Territorial estas unidades recobraran mucho más vigencia siempre y cuando se vean articuladas administrativamente en lo territorial para que procesos de gestión y de planificación sean el acopio de territorios mucho más dinámicos y fortalecidos en decisiones colectivas que lleven al verdadero desenlace politico y administrativo que viene dándose en el país por las diversas características de los territorios en lo ambiental y social y que en lo económico y administrativo nos refuercen globalmente en instituciones públicas mucho más fuertes que logren enmarcarse en las nuevas exigencias del mundo globalizado. Por ello, es fundamental tener el conocimiento en lo administrativo y territorial el desarrollo de las Unidades para la planificación pero que por sus características no han logrado mirarse o tenerse integralmente en decisiones colectivas.

A continuación se identifican las unidades para la zonificación territorial y cuales para el apoyo y fortalecimiento y como ellas se pueden manejar en el proceso de Postconflicto. Para llegar al planteamiento unificado en la Unidad de Gestión y de Planificación Territorial que logre administrativamente plantear un desarrollo territorial y armonizar los distintos instrumentos de planificación además de fortalecer la participación de sectores, gremio y sociedad civil e integral la red de asentamientos poblacionales teniendo en cuenta fundamentalmente su jerarquización funcional y espacial. 
Para La Zonificación Territorial

Unidades de Paisaje (UP)

Unidades Socioeconómico-Ambientales (USAG)

Unidades de Gestión Ambiental (UGA)

Unidades de Funcionamiento Espacial (UFE).

Fundamentos para un enfoque regional de desarrollo alternativo (ERDA)

Unidad de Planificación y de Gestión Territorial (UPGT)

Unidades Agrícolas Familiares (UAF).

Unidades Homogéneas desde la Estructura Ecológica Principal - (EEP)

Planeamiento Intermedio del Suelo Rural (PISR)

Unidad de Planificación Rural (UPR).

Unidades de Planificación y Administración Regional (U-PAR).

Unidades de Actuación Urbanística (UAU).

Apoyo Conceptual Para El Fortalecimiento De Las Unidades

Zonificación Ecológica Económica. (EE)

Comités de Integración Territorial (CIT).

Estructura Ecológica Principal. (EEP)

Conformación Regional desde la Cuenca Hidrográfica. (CRCH)

Diseño de un Organismo de Cuencas como Unidad de Administración Territorial.

Consejo de Cuencas. (CCS)

Comité de Cuencas. (CC)

Centros Provinciales de Gestión Agroempresarial (CPGA).

Regiones Administrativas y de Planificación (RAP).

Para los procesos de consolidación de la Paz, en términos de postconflicto.

Unidades Administrativas Especial para la Consolidación Territorial. (UAECT). La puesta en conocimiento de las Unidades de Gestión y de Planificación en términos de fortalecimiento institucional, se sustenta directamente en el soporte del apoyo conceptual para el fortalecimiento de las mismas unidades, teniendo en cuenta que Colombia le está apostando al desarrollo y consolidación de las regiones de planificación y al nuevo orden político-administrativo. Para ello el proceso de Postconflicto se convierte en el eje estructural para el avance y consolidación de nuestro estudio. Como se puede observar en la gráfica siguiente. 
Grafica. Estructura para el avance y consolidación de nuestro estudio.

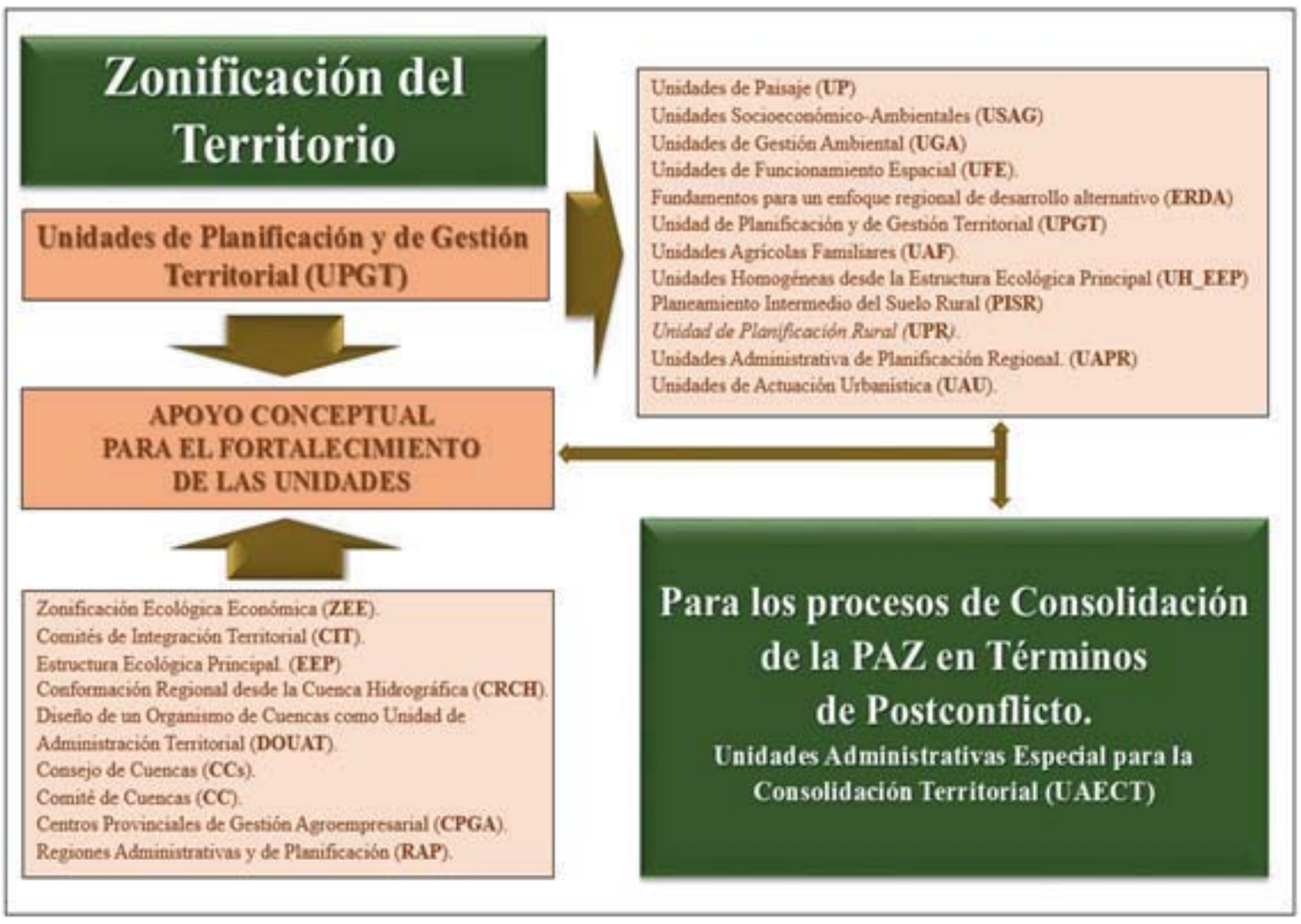

Fuente: Elaboración propia

\section{Restultados.}

Visión internacional y nacional en la aplicación de las Unidades de Planificación Territorial y de Gestión.

En distintos contextos de las naciones se han venido desarrollando aproximaciones y desarrollo al concepto de Unidades de Planificación Territorial, algunas de ellas al desarrollo productivo, otras al fortalecimiento politico e institucional, como también al mejoramiento de la calidad ambiental de nuestros territorios, teniendo en cuenta las directrices para el ordenamiento y planificación territorial.

Por lo tanto, el objetivo fundamental de la Planificación y Gestión del Territorio debe ser la de corregir los desequilibrios territoriales con el objetivo de mejorar la calidad de vida y armonizar la utilización de los recursos con la protección de la naturaleza. La mayor parte de los Planes de Ordenación y las Políticas de Desarrollo, a pesar de los considerables recursos destinados a las áreas menos desarrolladas no han sido suficientes para la eliminación de las disparidades territoriales, lo cual, nos da como resultado en gran número de unidades empleadas en innumerables conceptos dese visiones económicas, productivos, administrativos entre otros. 
Para Cataluña (España), la Unidad de Paisaje está directamente relacionado con el Ordenamiento Territorial, y es apoyado con los documentos de carácter técnico denominados "Los catálogos de Paisaje" que la Ley de protección, gestión y ordenación del paisaje de Cataluña 2005 concibe como herramienta para la ordenación y la gestión del paisaje desde la perspectiva del planeamiento territorial, [3]. Según, Joan Nogué 2010, dichos catálogos de paisaje deben orientar la integración del paisaje en los instrumentos de ordenamiento territorial a distintas escalas, desde los planes territoriales parciales hasta el planeamiento urbanístico, pasando por los planes directores y urbanísticos, lo cual, se convierte en la pieza básica de la planificación territorial para Cataluña; Para obtener un tipo de resultados aplicables y muy específicos metodológicamente se plantean cinco (5) fases para la elaboración de los catálogos.

- Identificación y caracterización del paisaje.

- Evaluación del paisaje.

- Definición de los objetivos de la calidad del paisaje.

- Establecimiento de directrices, medidas y propuesta de actuación.

- Establecimiento de indicadores de seguimiento.

\section{Unidades Socioeconómico-Ambientales (USAG)}

Si evaluamos contextos en su similitud rural, Colombia y España las podemos encontrar, si en términos ambientales estamos incorporando el tema de Unidades de Planificación Territorial, ya que se presentan estructuras complejas similares en la ocupación y uso del suelo, ecosistemas con un alto grado de diversidad ambiental, con los problemas específicos si entendemos que las áreas rurales proporcionan recursos, bienes y servicios que la población utiliza, el área rural es el receptor de impactos en los proyectos localizados en la función final del desarrollo y crecimiento de nuestras ciudades, como son la disposición final de residuos sólidos y emisarios finales en el manejo de los tratamientos de las excretas de las aguas servidas del crecimiento de los centros poblados localizados en sus áreas de influencia (Lopez, Serrano Montero, \& Martinez, 2000).

\section{Unidades de Gestión Ambiental (UGA)}

Para el caso de Costa Rica en las Federaciones de gobiernos locales en seis municipalidades se utilizó la Unidad de Gestión Ambiental, lo cual, no pretendía remplazar las unidades ambientales dentro de cada una de las municipalidades, consejos municipales o distritos, sino más bien contribuir con el soporte técnico a cada gobierno local d acuerdo con la estructura que estos posean para gestionar proyectos estratégicos regionales en beneficio de las comunidades las cuales están representadas en cada una de las unidades. (Nogué, 2010); (Global Water Partership, 2009). Dentro de las fortalezas institucionales las Unidades de Gestión Ambiental brindan el apoyo a gobiernos locales, alcaldes, intendentes, funcionarios 
municipales y a la vez a las unidades que se vayan conformando dentro de cada una de las municipalidades.

Para el caso de Nicaragua la Unidad de Gestión Ambiental (Uga) es una división de la Federación de Gobiernos Locales Fronterizos con Nicaragua, conocidos con la sigla (Fglfn), brindan las mismas características fijadas en Costa Rica, y la integración y coordinación de los esfuerzos realizados por diferentes actores en el tema ambiental. Las (Fglfn) poseen una división encargada de brindar asesoría y seguimiento en el tema ambiental, constituye una forma de atender los problemas prioritarios con un enfoque estratégico y regional, como también está diseñada para que se constituya en una entidad de gran relevancia dentro de la Fglfn. Por tal razón la Uga debe estar liderada por un coordinador que responda directamente a la Dirección Ejecutiva de la Fglfn. (Nogué, 2010) El costo salarial y administrativo para la instauración de la Uga deberá ser parte del presupuesto de la Fglfn. Una vez instalada la Uga se deberá establecer como meta que sea autosostenible, es decir, que genere a través de proyectos, recursos suficientes para cumplir con los objetivos y metas establecidos en el Plan Estratégico.

El Plan Estratégico como planificación debe responder a dos preguntas: ¿hacia dónde vamos?, ¿cómo vamos a llegar ahí? Se define el destino al que se pretende llegar en los siguientes años (de 3 a 5). Por lo tanto se recomienda seguir los siguientes pasos: Definición del cronograma para la elaboración del Plan Estratégico de la Uga; Análisis de la situación actual del tema ambiental en la región; Definir y revisar la politica ambiental; Definir y revisar la misión y la visión de la Uga; Definir los objetivos estratégicos; Definir los indicadores estratégicos y las metas; y presentar el Plan Estratégico de la Uga ante el Concejo Directivo.

\section{Unidades de Funcionamiento Espacial (Ufe).}

El Instituto Geográfico Agustín Codazzi Igac, promocionó la creación dela Unidades Funcionales Especiales para que los municipios en el año 1991 ampliarán el criterio de estructurar el análisis territorial, lo cual, debería dar como resultado la orientación de infraestructura vial para la prestación de servicios entre ellos: escuelas, centros de salud, inspecciones; también orientar la delimitación de Corregimientos, Comunas, Asociación de municipios, Veredas, Barrios y zonificar el territorio a través del concepto de subregionalización. Dentro de ellas y encuentran en la mayoría de los casos centro que polarizan el área local, y áreas de influencia de servicios públicos), las relaciones del entorno rural y urbano regional, es la división del territorio. El análisis del sistema de funcionamiento espacial tiene que ver con las formas de asentamiento de la población, su funcionamiento los flujos que se presentan dentro del municipio, desde él y hacia él las cuales dependen de las características sociales, de infraestructura, ambientales y económicas. (Davoudi, 2007)

Erda, Fundamentos para un enfoque regional de desarrollo alternativo. (Cider, Universidad de los Andes). 
Para asuntos de ampliar el marco de referencias en términos de unidades, en el año 1996 la Universidad de los Andes a través del Centro Interdisciplinario de Estudios Regionales conocido con la sigla Cider. El arquitecto Adolfo Izquierdo Uribe, en su ponencia presentada en el II Seminario de Investigación Urbano Regional sobre la investigación urbana: "Retos para el desarrollo" organizado por la Asociación Colombiana de Investigadores Urbanos Regionales Aciur en octubre de 1996.

\section{Unidades Agricolas Familiares (Uaf).}

La ley 160 de 1994 Inspirada en el precepto constitucional "por el cual es deber del Estado promover el acceso progresivo a la propiedad de la tierra de los trabajadores agrarios a otros servicios públicos rurales con el fin de mejorar la calidad de vida d la población campesina...", (Artículo $1^{\circ}$ ). En el Capítulo IX en su artículo 38 establece las Unidades Agrícolas Familiares y Parcelación Uafp. "Cuya definición es la empresa básica de producción agricola, pecuaria o forestal cuya extensión conforme a Las condiciones agroecológicas de la zona y con tecnología adecuada permita a la familia remunerar su trabajo y disponer de un excelente capitalizable que coadyuve a la formación de su patrimonio". Documento que establece la relación de las Uaf con los Pot's (Cdim, 2010).

\section{Unidad Administrativa Especial para la Consolidación Territorial. (Uaect)}

A partir de la promulgación de la Ley 1450, por la cual se aprobó el Plan Nacional de Desarrollo 2010-2014, en su artículo 195, indica que: "el direccionamiento estratégico de la Politica Nacional de Consolidación Territorial será responsabilidad del Consejo de Seguridad Nacional" (Ley 1450, 2011). Siendo de interés de Estado, el tema de la consolidación y el ordenamiento territorial, entendido en pro del proceso en la solución del conflicto armado, se crea por el Decreto 4161, del 3 de noviembre, La Unidad Administrativa Especial para la Consolidación Territorial (Decreto 4161, 2011), y se determinan los objetivos, estructura y funciones. Por lo tanto, tiene como objetivo principal la implementación, ejecución, y hace el seguimiento a la Politica Nacional de Consolidación Territorial; canalizando, coordinando y articulando la intervención institucional diferenciada en las distintas regiones de consolidación focalizadas y en las zonas afectadas por los cultivos ilícitos y conflicto armado. Se puede determinar que aquí se plasma por parte de un instrumento de planificación y de gestión territorial e tema de la solución en la participación del Estado Colombiano en el tema de Postconflicto. (Decreto 4161, 2011) creándose una unidad administrativa y de gestión para el tema de Postconflicto.

\section{Unidades De Planificación En El Territorio Desde Lo Ambiental}

"La percepción del Decreto 3600 del 20 de Septiembre de 2007" (Decreto 3600, 2007); Las Unidades de Planificación que reconoce el Decreto 3600 de 2007, reglamentario de la ley 388 de 1997, busca la intervención en áreas rurales en desarrollos determinados de inmuebles, desarrollo industrial, pero a la ves proporciona el régimen de usos para dichas actividades. 
Las Unidades de Planificación se contextualizan teniendo en cuenta, las bases de intervención económica en las actividades de ocupación territorial, esto quiere decir, que la vivienda tendrá a la A.) Unidad Mínima de Actuación, al igual que su conformación de inmuebles con utilización industrial, en términos de uso del suelo, se puede plantear la B.) Unidad de Planificación Rural, donde se determinen las Áreas de conservación y protección ambiental establecidas por la legislación vigente, tales como: I) Las áreas del sistema nacional de áreas protegidas, II) Las áreas de reserva forestal, III) Las áreas de manejo especial, IV) Las áreas de especial importancia ecosistémica, tales como: páramos y subpáramos, nacimientos de agua, zonas de recarga de acuíferos, rondas hidráulicas de los cuerpos de agua, humedales, pantanos, lagos, lagunas, ciénagas, manglares y reservas de flora y fauna, V) Áreas para la producción agrícola y ganadera y de explotación de recursos naturales, VI) Áreas e inmuebles considerados como patrimonio cultural, VII) Áreas del sistema de servicios públicos domiciliarios, VIII) Áreas de amenaza y riesgo.

\section{Diseño De Un Organismo De Cuencas Como Unidad De Administración Territorial}

Algunos aspectos básicos que se consideran en el proceso de planificación y manejo y ordenación de cuencas hidrográficas, ha sido la delimitación como unidad de planificación territorial. Resulta que los limites de las veredas a través de comunidades rurales, poblaciones, municipios, departamentos, provincias son diferentes a los limites naturales, salvo en algunos casos donde coinciden con el trayecto del río y muy pocas coinciden con las divisorias de agua. Por lo tanto, para el diseño del organismo de cuencas como Unidad Administración en el territorio, se debe proceder a la delimitación de la cuenca a través de las subunidades, dependiendo del análisis y argumentación del diagnóstico de los POTs y de los POMCAS, con énfasis para la planificación; necesariamente se debe concertar con los actores locales, con los interesados en cada una de las subunidades que deben ser determinadas para ser elevadas como unidades administrativas. Lo importante es identificar las variables que articulen o determinen las relaciones intra-territoriales entre las relaciones de cada una de las Subunidades de Gestión y Planificación Territorial, determinadas en el área total. (Faustino \& Benegas, 2008)

El enfoque del diseño del Organismo de Cuencas como Unidad de Administración Territorial, como sistema de gestión permite entender mejor las interacciones ambientales, sociales y económicas, condiciones claves dentro de un enfoque integral e interdisciplinario, se pueden caracterizar los siguientes argumentos los cuales fortalecen la administración del territorio:

- Cada una de las subunidades como sistema nos permite entender mejor las interacciones ambientales, físicas, sociales y económicas las cuales son condiciones claves para desarrollar un enfoque integral e interdisciplinario en el territorio a través de la gestión y administración territorial.

- .La Subunidad de Gestión y planificación define una unidad natural, con límites físicos y un funcionamiento dinámico, que permite localizar la Unidad de Administración Territorial denominada como organismo de cuenca describe 
escenarios para las tomas de decisiones para planificadores y, administradores territoriales.

- La Subunidad de Gestión y planificación con su sistema hídrico, posibilita importantes evaluaciones de intervención sobre el medio fisico, para interpretar los conflictos y usos apropiados de las diferentes subunidades componentes. La cantidad y calidad del agua constituyen los elementos claves para la toma de decisiones.

- El manejo y administración de cada una de las subunidades, define un territorio con dominio de factores sociales y económicos sobre el medio físico, se enfoca hacia la Unidad de Gestión Territorial; base principalmente para la toma de decisiones sobre estas unidades o cuales son los factores que inducen estas decisiones, luego el manejo de cada subunidad de Gestión y Planificación Territorial define una base de gestión por parte de sectores de agricultores, ganaderos usuarios y beneficiarios de los recursos naturales.

\section{Consejo de Cuencas}

La creación del Consejo de Cuenca se hará dentro de las competencias y responsabilidades establecidas en el (Global Water Partership, 2009) Manual de la Gestión Integral del Recurso Hídrico, además lo dispuesto en la resolución 0509 de mayo de 2013 del ministerios de Medio Ambiente, como instancia decisoria para la conformación de los Consejos de Cuenca en acciones orientadas al ordenamiento y administración del territorio por medio del reconocimiento previo de cada una de las Unidades de Planificación en lo que a la zonificado del territorio se refiere. Los lineamientos estarán dados hacia el manejo y la conservación, protección, preservación y restauración de los recursos naturales allí presentes; a esta instancia se le denominará "Consejos de Cuenca", la jurisdicción del consejo es netamente participativo hacia la integración del sector privado y sociedad civil con el sector público, con jurisdicción local, el esquema de participación y articulación de los actores sociales propuesto previamente, los Consejos de Cuenca estarán determinados dentro de la jurisdicción de cada una de las Unidades de Planificación. El objeto es de fortalecer los mecanismos de participación de las Unidades de Planificación. Los Consejos de Cuencas, se reconocerán como la instancia participativa en la deliberación de proyectos planteados a través de los Pomca y de los Pot's - Municipales, como de proyectos gestionados y su localización estará desde las dinámicas reconocidas en los resultados de las Dimensiones del Desarrollo, la cual, basados en la Ley 617 de 2000, se determina la nueva recategorización de las entidades territoriales que logren su mejor desempeño y gestión fiscal a través de su capacidad de gestión administrativa y fiscal.

\section{Comité De Cuencas}

El Comité de Cuenca para la Gestión del Ordenamiento y el Manejo Ambiental del territorio, debe estar involucrada de forma indispensable toda la población. El Comité de Cuenca, se rige bajo los parámetros siguientes de la Asociación Mundial para el Agua (Gwp): La planificación, La organización, La toma de decisiones, La coordinación, El control y El mejoramiento de la eficiencia en los resultados de la administración y en uso del suelo y la distribución de responsabilidades. 
En la Figura siguiente., se identifican los contextos administrativos con algunos instrumentos, con los cuales se debe armonizar el territorio. Los UGPT, como instrumentos de gestión son cruciales para la toma de decisiones al articular los Planes de desarrollo y Planes de Ordenamiento territorial entre otros. Es de vital importancia el conocimiento y la valoración cualitativa y cuantitativa del territorio; se debe orientar a futuro y resaltar las limitaciones, establecer la capacidad de uso, la localización y detección de los bienes y servicios de que dispone o proporciona el territorio. Igualmente se debe incidir la dimensión social, ambiental, económica y administrativa, pues se considera que estas dimensiones éste influyen de manera importante para la toma de decisiones para la armonización de los distintos instrumentos de gestión. Tomado del trabajo de tesis de Magister Ernesto Villegas Rodríguez registrado en la base Sedici - Unlp DE Argentina (Villegas Rodriguez, 2014), Propuesta de lineamientos conceptuales y metodológicos para la planificación de la gestión sostenible de la cuenca hidrográfica del río Bogotá, desde una perspectiva regional.

Grafica 2: La Armonización De Los Instrumentos De Planeación Y De Gestión Territorial

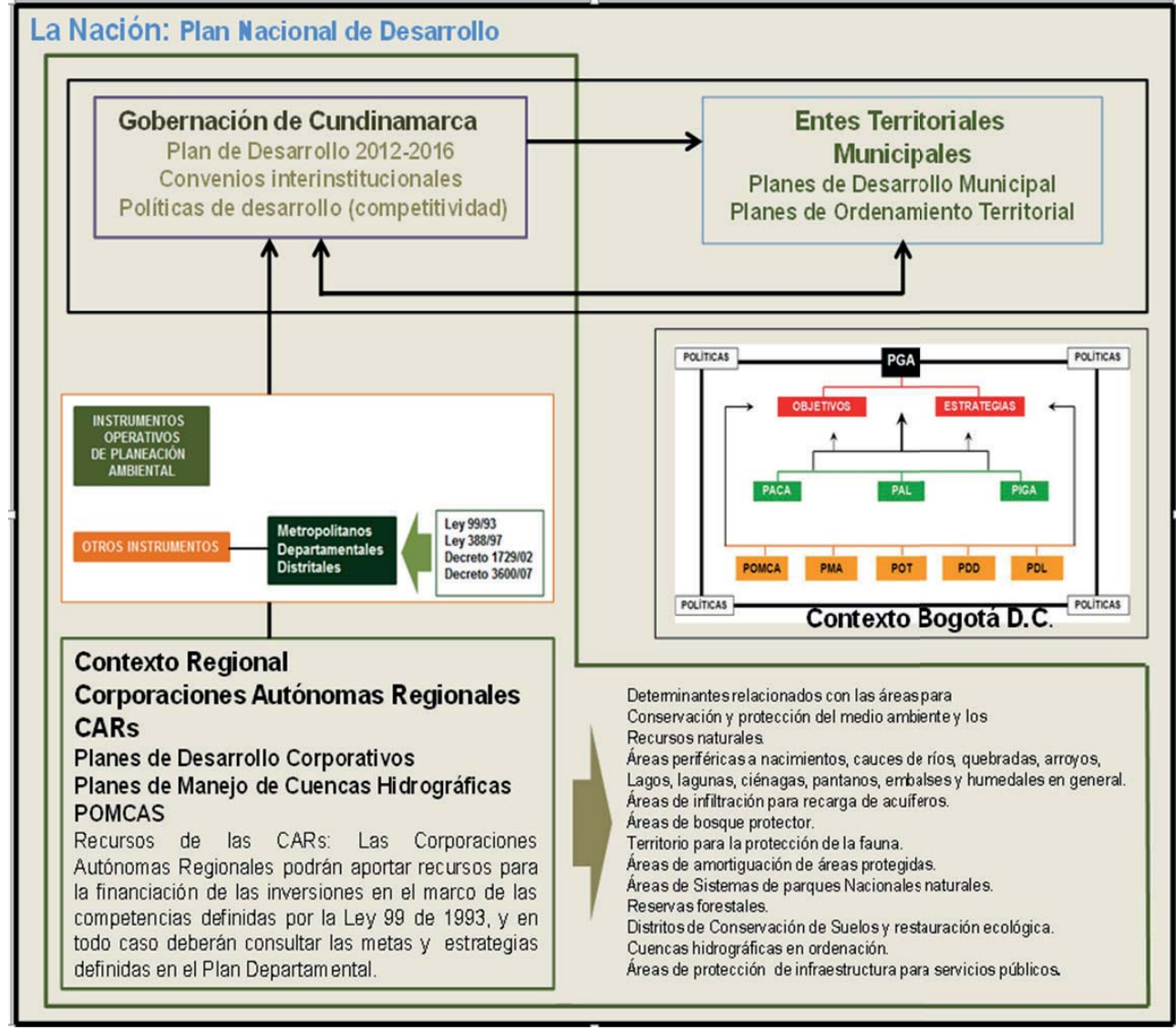

Fuente: Elaboración propia. Magister Ernesto Villegas Rodríguez registrado en la base SEDICI UNLP DE Argentina. Propuesta de lineamientos conceptuales y metodológicos para la planificación de la gestión sostenible de la cuenca hidrográfica del río Bogotá, desde una perspectiva regional. Unidad de Planificación y de Gestión Territorial (UPGT) 
La propuesta de la investigación central es la de iniciar con la Cuenca Hidrográfica o los acuíferos como la Unidad que constituye la Unidad de Planificación y de Gestión Territorial (Upgt) como la más apta para la Ordenación, Planificación y Gestión en el Territorio, coordinada a través de la organización de los recursos hídricos y la gestión del mismo en el territorio, no se reconoce fronteras político-administrativas sino leyes físicas. En el contexto de Colombia se han venido promulgando dos Decretos de carácter de Ley los cuales como es el caso del Decreto 1729 de 2002, proporcionan los lineamientos para la reglamentación la ordenación y manejo de cuencas hidrográficas denominadas como Unidades Básicas de Gestión, metodológicamente desarrollada en seis fases: a). Aprestamiento, b) Diagnóstico, c) Prospectiva, d) Formulación, e) Ejecución f) Seguimiento y Evaluación. Y el Decreto 1640 de 2012, que reglamentan los instrumentos para la Planificación, Ordenación y Manejo de las Cuencas Hidrográficas y Acuiferos, se resalta la importancia para la coordinación de la Planificación, Ordenación a través del Consejo Ambiental Regional de la cuenca a través de la Comisión Conjunta.

Armonización territorial, hacia la segunda generación de los instrumentos de planificación y de gestión.

Con los argumento necesarios para la armonización entre entidades territoriales, donde se localice uno o varios municipios teniendo en cuenta proyectos comunes que se definan a través de los planes de desarrollo teniendo en cuenta inversiones como también la puesta en marcha de algunos proyectos de localización definidos por los Planes de Ordenamiento Territorial (Pot) y Planes de Manejo de Cuencas Hidrográficas (Pomcas), estos deberán tener en cuenta en sus propios ámbitos de competencias determinados por las decisiones en la Zonificación Ambiental Territorial que tanto por los Pot's y Pomcas; el componente programático y el componente de gestión del riesgo, según lo dispuesto en el artículo 10 de la Ley 388 de 1997. (En el caso de la ordenación de cuencas hidrográficas es considerada como norma de mayor jerarquía a los Pot's municipales). Serán las bases para la armonización entre territorios que puedan ejecutar programas y proyectos en conjunto en los cuales las sinergias conlleven a una mejor utilización de recursos financieros de inversión como de capital humano entre distintas administraciones municipales o departamentales, fortaleciendo así el tema de la institucionalidad. En la siguiente grafica se muestran las relaciones o vínculos para el planteamiento de la armonización. 
Gráfica 3: Zonificación ambiental con base en los instrumentos de planificación.

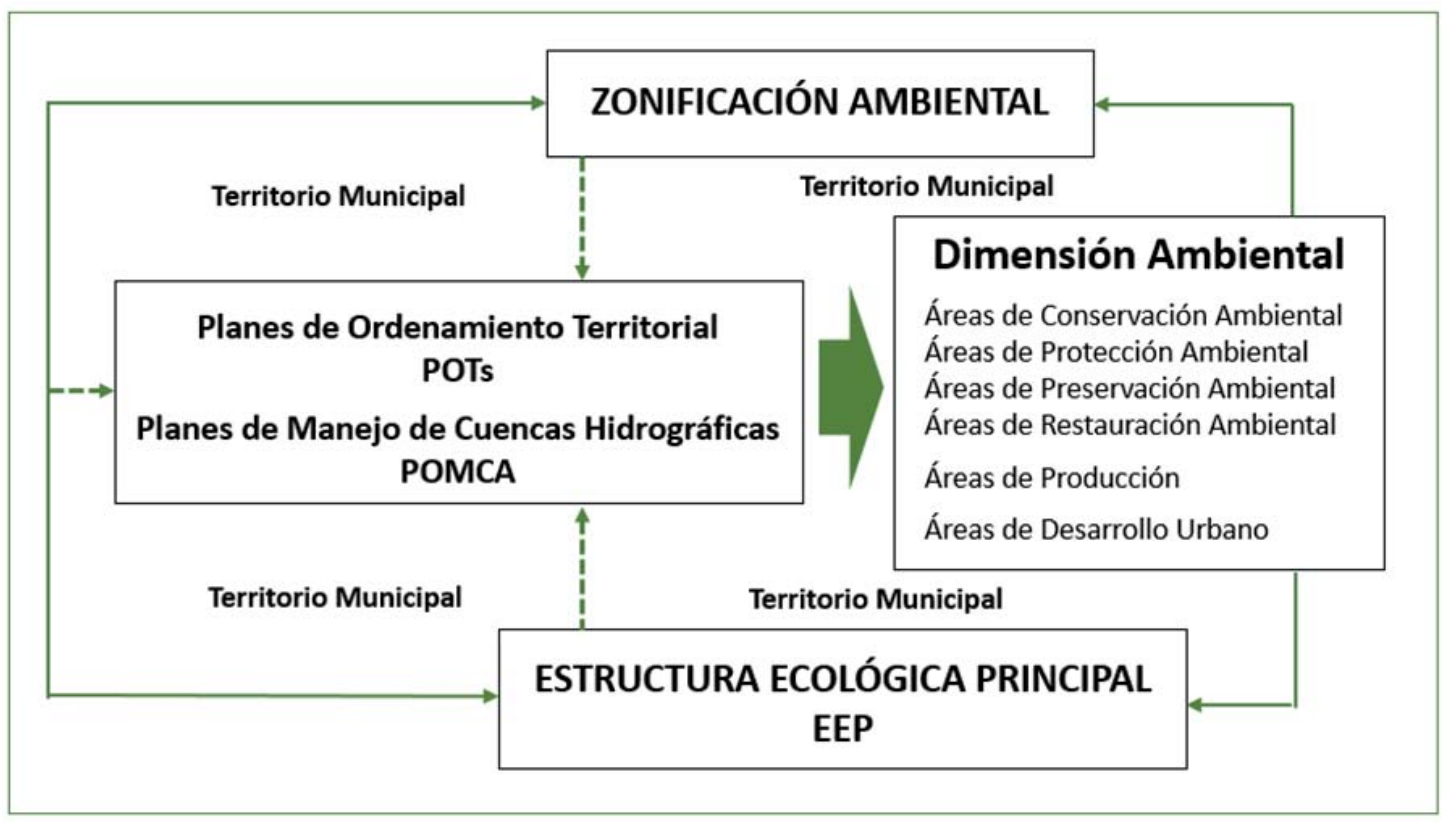

Fuente: Elaboración Propia.

Para el manejo de la propuesta metodológica de las Unidades de Planificación y de Gestión Territorial (Upgt), se debe tener en cuenta el conjunto de elementos bióticos y abióticos que dan sustento a los procesos ecológicos esenciales del territorio, además de las condiciones establecidas en términos de desarrollo y crecimiento de cada uno de los territorios involucrados en la asociación, lo cual, es acreditada teniendo en cuenta los principios de ordenación de la Estructura Ecológica Principal Eep, (Decreto 3600 de 2007 - 1729 de 2002 y 1640 de 2012), lo que permite la asociación e integración de municipios que comparten ecosistemas similares como proyectos y decisiones institucionales comunes. En el año 2013 en el mes de diciembre se promulgaron dos Resoluciones por parte del Ministerio de Ambiente y Desarrollo Sostenible: la primera la 1907 de diciembre 2013, por la cual, se expide la Guía Técnica para la formulación de los Planes de Ordenamiento y de Cuencas Hidrográficas; y la segunda resolución 0509, por la cual se dan los Lineamientos para el Desarrollo de los Comités de Cuencas y los Consejos de Cuencas, determinantes como instrumentos de gestión que fortalecen los lazos en el manejo de la sostenibilidad ambiental regional en la utilización en la conservación, preservación, restauración ambiental, en el desarrollo de proyectos de producción además de fortalecer la red de ciudades según su propia jerarquización espacial actual y futura promovida por los Pot y Pomcas.

Lo anterior, se traza a partir del año 2014 como aporte a la visión para la planificación territorial la nueva interpretación del ordenamiento territorial conocidos como los Pot's y Planes de Desarrollo lo cual se llamaria “De segunda generación”, teniendo las condiciones de estar al tanto de la cuenca como unidad de gestión territorial, asumiendo la Eep como elemento de decisión de gestión para la preservación, 
conservación y restauración ambiental, la producción y el desarrollo urbanístico de las ciudades localizadas e identificadas en el área de consolidación territorial, como las condiciones de mantener un desarrollo territorial sostenible.

Grafica 4. Metodología Armonización entre la Ley 388 de 1997 y el Decreto 1729 de 2002

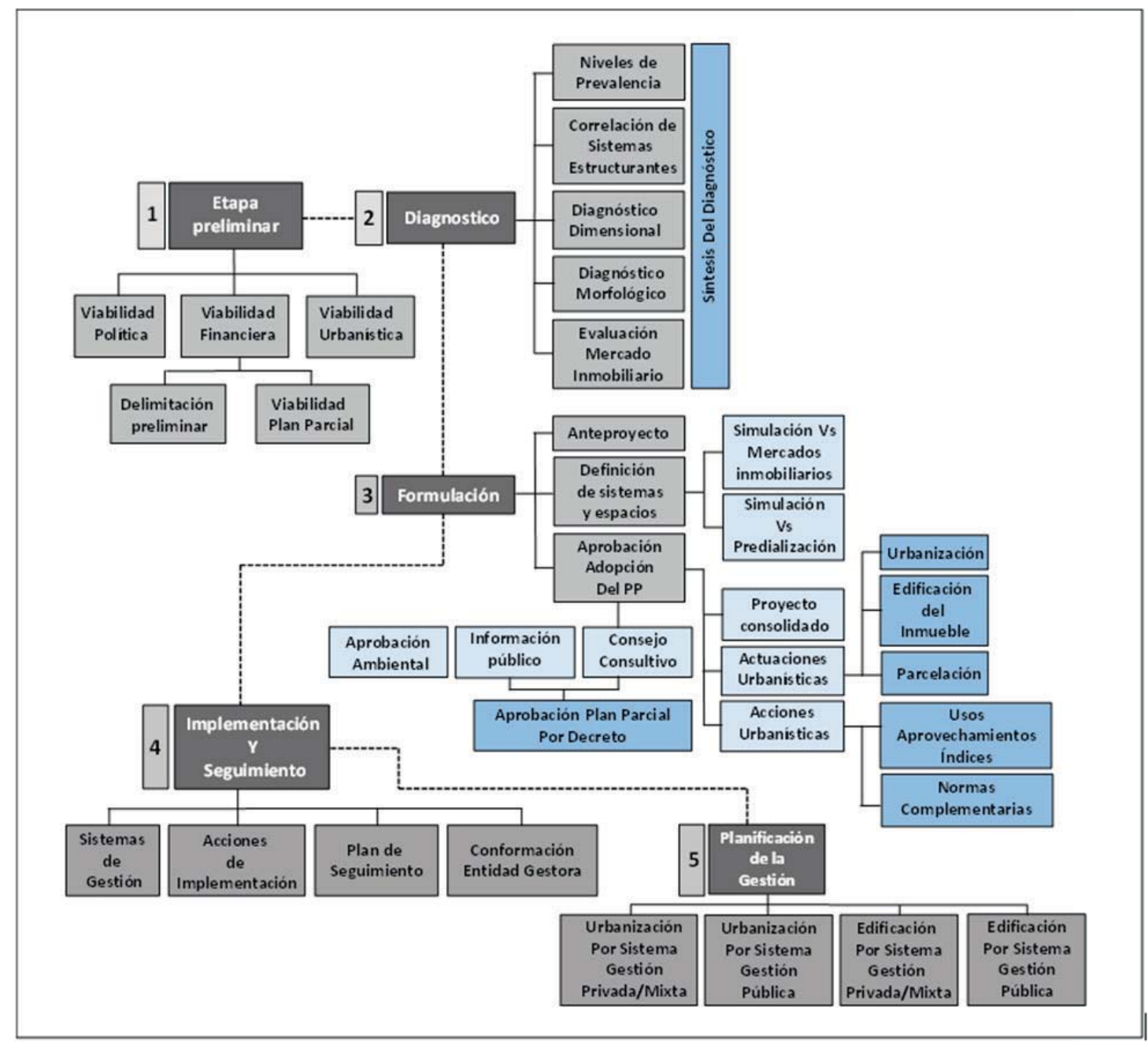

Fuente: Elaboración propia - estudio la Unidad de Planificación territorial y de Gestión, como instrumento operativo para la toma de decisiones urbano rural.

\section{Planificación en la Gestión Urbana.}

Corresponde al planeamiento del conjunto de decisiones, procesos y acciones que realizados de forma articulada mediante los instrumentos de reparto de cargas y beneficios, de intervención de la estructura predial, la intervención de la intervención sobre el derecho de propiedad y de intervención financiera, convierten las decisiones de planeamiento en espacios urbanos construidos de forma 
ambientalmente sostenible con el fin de aportar a la disminución del calentamiento global y/o calentamiento global.

Sin embargo, la cooperación entre participes es utilizado como mecanismo de gestión sobre el suelo utilizado para el reparto equitativo de cargas y beneficios en el desarrollo de actuaciones urbanísticas que no requieran de una nueva configuración predial de sus superficie y las cargas y beneficios garantizando la cesión de terrenos y el costo de las obras de urbanización correspondientes.

Desarrollo, puedan ser repartidas en forma equitativa entre sus propietarios, garantizando la cesión de terrenos y el costo de obras de urbanización correspondiente. Con motivo de aclarar las denominadas "cargas" las cuales son los sistemas Estructurantes propuestos y desarrollados por la administración municipal o distrital, y las denominadas "beneficios" son aquellas que por las actividades del municipio o distrito, los predios privados generan utilidades a los particulares en edificabilidad, construcción y ocupación.

Es el territorio sobre el cual se pretende intervenir la propuesta urbanística teniendo en cuenta las características utilizadas en la Ley 388 de 1997 y sus decretos reglamentarios; algunos términos utilizados en el desarrollo urbanístico se denominaron operaciones urbanas, se encuentra determinada en los Planes de Ordenamiento Territorial de cada uno de los municipios o en las normas que lo complementan. Como se puede observar en el esquema metodológico de la gráfica siguiente.

Grafica 5. Metodología Gestión Urbana con visión Participativa y Sostenible.

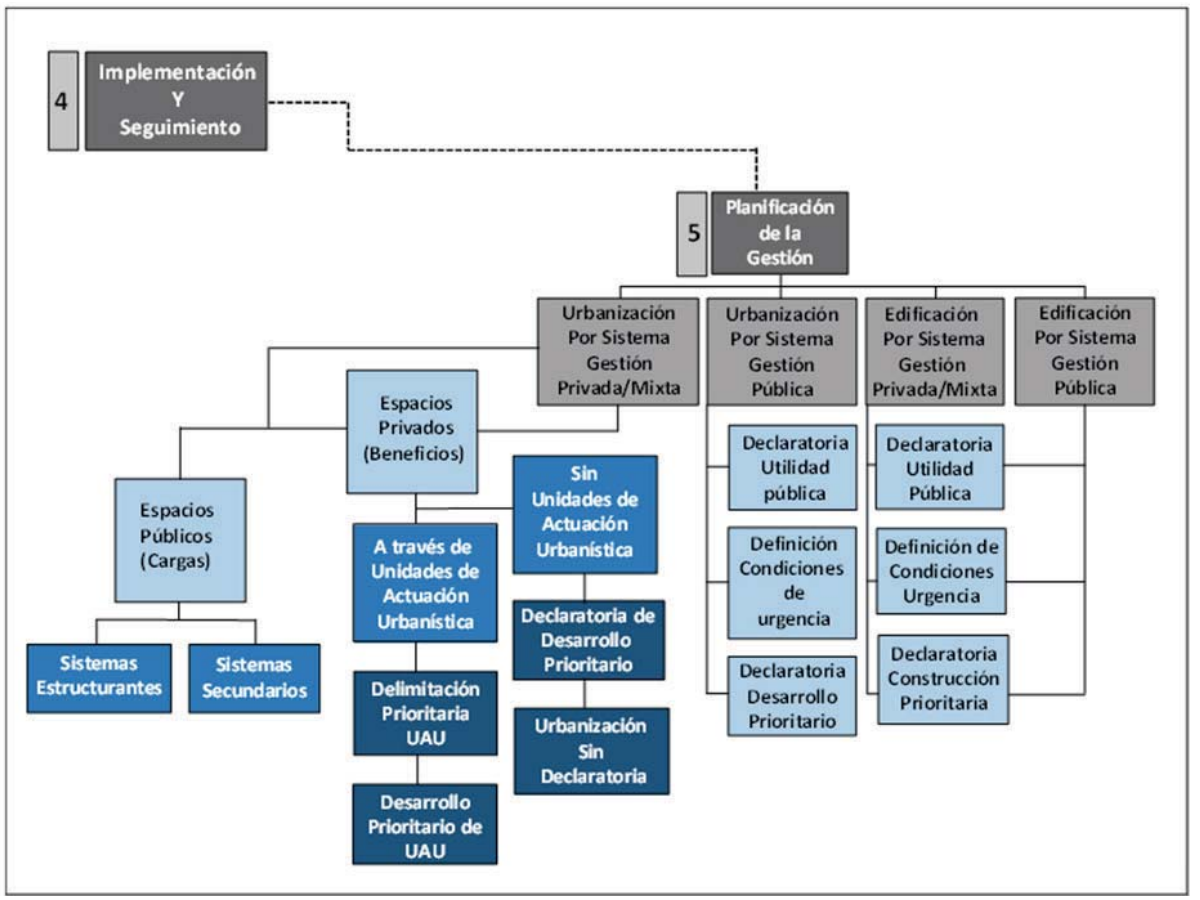

Fuente: Elaboración propia - estudio la Unidad de Planificación territorial y de Gestión, como instrumento operativo para la toma de decisiones urbano rural. 
Por consiguiente las leyes determinantes para planificación territorial y gestión como otros planes urbanos relacionados con el desarrollo territorial, pueden afectar el avance de los Planes de Desarrollo como también la visión determinada en la ocupación del territorio a través de los Planes de Ordenamiento Territorial. A menudo más importante, implantados y cuestionados como quién tiene voz en la formulación de un plan, quién tiene la capacidad de interpretarlo sancionarlo y quién posee suficiente información y recursos para desafiarlo, los cuales, pueden afectar fundamentalmente a millones de vidas concentradas en un marco referencial denominado territorio. Del mismo modo, las fuentes de financiación municipal y la forma en que se elaboran los presupuestos, también tienen un impacto importante en los intereses relativos de los actores o grupos protagonistas en la toma de decisiones que indudablemente involucran los procesos participativos y aplicación de referentes democráticos para hacerlos cumplir por las respectivas autoridades. Este diálogo desde el conocimiento del marco normativo, explora el papel de la legislación nacional a la hora de definir, demandar y alcanzar la equidad en áreas urbanas y rurales, con un énfasis especial en la experiencia en los países de la región. Cuyas determinantes de políticas públicas se han venido consolidando de tal manera que lo determinado en lo local influye o compromete otros contextos con mayor globalidad.

Teniendo en cuenta la evolución de la planificación municipal, a través de la ley 388 de 1997, lo cual permitió incorporar algunos componentes denominadas Dimensiones del Desarrollo en las áreas ambiental, social, económica, administrativa y territorial, mediante la cual se dispuso que los municipios manejaran de forma más integral el tema de desarrollo y crecimiento territorial, en la elaboración de un Plan de Ordenamiento territorial (Pot) de largo plazo integrando los programas y proyectos de Planes de Desarrollo a nivel Departamental y Municipal, centrado en dimensiones diseñadas integralmente para propiciar el desarrollo territorial. Esto tuvo como manifiesto en la forma de incorporar en el corto, mediano y largo plazo de una planeación económica prospectiva hacia la planificación regional y territorial y de la planeación física urbano rural, a una planeación integral y sostenible en asocio a la planeación técnica con planeación participativa. Lo cual se planteará con base en la figura anterior (Metodología Gestión Urbana con visión Participativa y Sostenible.

Hoy en día (2014) los municipios de Colombia, tienen en ejecución los Planes de Ordenamiento Territorial, bajo el esquema de concentración población de 01 hasta 20.000 habitantes denominado Plan Esquema de Ordenamiento Territorial (Peot), de 20.000 hasta 100.000 habitantes Plan Básico de Ordenamiento Territorial (Pbot),y más de 100.000 habitantes de ordenamiento conocido con la sigla Pot.

Es la forma con la cual se ha venido desarrollando la planificación territorial municipal, llegando a las dos décadas desde el dictamen de la Ley 388 de 1997 con esta experiencia. Por lo tanto, la planificación urbana y rural se ha venido constituyendo hasta hoy en día como el instrumento de planificación para propiciar el desarrollo y consolidación del desarrollo municipal hacia la visión de la región de forma muy sesgada en términos de la territorialidad, lo cual la región está muy lejana 
con este tipo de convocatorio en el desarrollo territorial para su conformación. Lo anterior, refleja en la planificación territorial visiones encontradas y contradictorias en hacer del ordenamiento, el instrumento de gestión, siempre y cuando se pueda deslumbrar dos posiciones y plantear la más viable: la primera teniendo en cuenta el número de población en el territorio y la segunda el territorio como extensión estratégica teniendo en cuenta el desarrollo social, económico y su consolidación politico y administrativa.

Lo anterior, sería determinante en la posición de las entidades municipales en el momento de escoger el tipo de ordenamiento territorial (Peot - Pbot - Pot). Cuyas directrices y lineamientos por donde se debe estructural el desarrollo y crecimiento se limitaría al tema poblacional y no a la territorialidad que tanto en lo político y administrativo refleja condiciones de estrategia funcional cuando la administración determina el alcance de desarrollo y sus condiciones de participación ciudadana en el conocimiento a la información en temas de desarrollo ambiental. La consideración de la población o sociedad civil es el eje fundamental sobre el cual se debe proyectar el crecimiento y sobre quien recae la toma de decisiones, por ello, es fundamental la participación ciudadana tanto en los denominados Planes de Desarrollo y Planes de Ordenamiento Territorial (departamental, municipal) es así como se debe integral la visión regional al articular los denominados Planes de Ordenación y Manejo de Cuencas Hidrográficas (Pomca).direccionados desde las Corporaciones Autónomas Regionales (Car) y los Pot direccionados por las entidades municipales.

Finalmente, la construcción de la planificación regional ha requerido gran eficiencia institucional, teniendo en cuenta las ultimas promulgaciones de las políticas públicas, de las cuales depende su aplicabilidad y capacidad de gestión en sus diferentes niveles de prevalencia, desde lo nacional hasta lo municipal, de esta forma se genera un mejoramiento en la gestión y fortalecimiento institucional y su articulación hacia la sociedad que es el objetivo central hacia el mejorando de su calidad de vida. Las bases generales para la actuación pública en el planeamiento urbano y de la gestión del suelo, permite establecer un marco de referencia para enfrentar los principales desafíos del desarrollo urbano en interrelación con el área rural en el marco de la política y desarrollo de la globalización. La experiencia en el mejoramiento de la calidad de vida en La ciudad y el aumento de sus índices de productividad se ha fundamentado en lo general, en la puesta en marcha de la práctica efectiva y coherente del fortalecimiento institucional a través de la planeación y la gestión del suelo; implicando acciones en cuatro frentes: 
Gráfica 6. práctica efectiva y coherente del fortalecimiento institucional a través de la planeación y la gestión

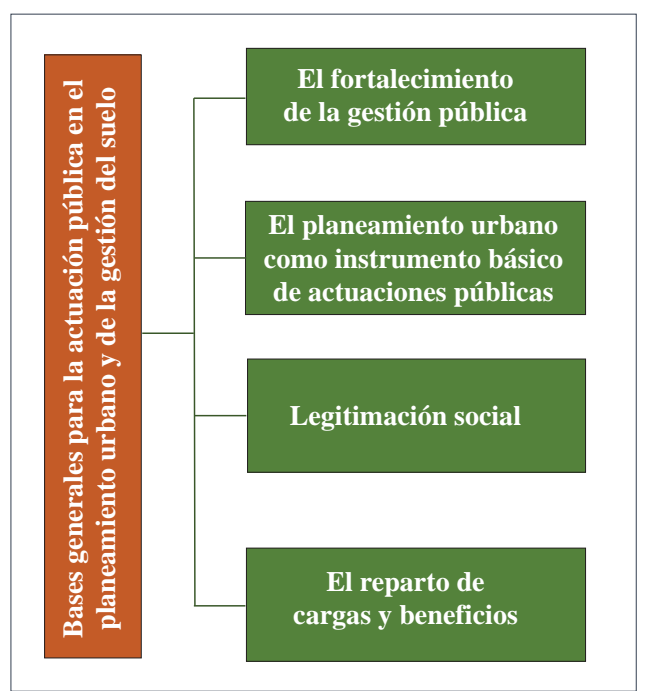

Fuente: Elaboración propia.

Estos cuatro (4) elementos se fundamentan en el establecimiento del régimen legal, normativo y jurídico de las políticas públicas de la propiedad del suelo, que define con precisión los derechos y obligaciones de los propietarios de los terrenos implicados en el desarrollo urbano, con respecto a los procesos de urbanización y construcción, lo cual, debe partir de los preceptos constitucionales, entre la función social de la propiedad, la posibilidad de intervención del Estado en el uso del suelo y los servicios públicos para conseguir mejoramiento de la calidad de vida, el derecho de las entidades públicas a participar en la plusvalía que genere su acción urbanística, la prevalencia del interés general, el deber del Estado de velar por la protección de integralidad del espacio público, el deber del Estado de proteger la diversidad del ambiente, entre otros. El Artículo 6 del Decreto 3600/07, para desarrollar y precisar las condiciones del ordenamiento municipal en áreas específicas del suelo rural, el plan de ordenamiento territorial podrá delimitar para la totalidad del suelo rural en Unidades de Planificación Rural (UPR), teniendo en cuenta, por lo menos, los cinco aspectos siguientes:

- La división Veredal.

- La red vial y de asentamientos existentes.

- La estructura ecológica principal.

- La disposición de las actividades productivas.

- Las cuencas hidrográficas, cerros y planicies u otros elementos geográficos.

Por lo tanto, las Upr, deben complementarse directamente cuando no hayan sido examinados directamente en el plan de ordenamiento territorial (Pot), como mínimo, los siguientes aspectos los cuales deben tener directamente la Estructura Ecológica Principal como elemento de ordenación y de gestión: 
- Las normas para el manejo y conservación y protección.

- Uso y manejo de las áreas destinadas a la producción agrícola, ganadera, forestal, de explotación de los recursos naturales, agroindustrial, ecoturística, etnoturística.

- Localización de las infraestructuras básicas relativas a la red vial nacional y regional, puertos y aeropuertos, y las directrices de ordenamiento para sus áreas de influencia.

- Suelo rural suburbano, la definición del sistema vial, el sistema de espacios públicos, la determinación de los sistemas de aprovisionamiento de los servicios públicos de agua potable y saneamiento básico, así como de los equipamientos comunitarios.

En términos de reglamentación las Unidades de Planificación, deberá complementar los aspectos normativos para el desarrollo de cada una de las Unidades propuestas en relación a los beneficios de las acciones urbanísticas que constituyen hechos generadores de la participación en la plusvalia, las cuales deberán ser tenidas en cuenta, en conjunto o por separado, para determinar el efecto de la plusvalía. (Ley 388, 1997) (Capítulo IX de la Ley 388 de 1997). Como también, algunas normas para impedir la urbanización de las áreas rurales que limiten con suelo urbano o de expansión urbana. Sin embargo, la Unidad de Planificación, también podrá incluir la definición de los distintos tratamientos o potencialidades de utilización del suelo y las normas urbanísticas específicas sobre uso y aprovechamiento del suelo que para el desarrollo de las actuaciones de parcelación y edificación de las Unidades Mínimas de Actuación se hayan definido en el plan de ordenamiento territorial y que hacen parte integral de las Unidades de Planificación Rural.

Para las características de la planificación de la gestión, se pueden identificar cuatro instrumentos el de urbanización por sistema de gestión Privada/Mixta; Urbanización por sistema de gestión pública; Edificación por sistema de gestión Privada/Mixta y Edificación por sistema de gestión pública. En lo referente de cargas urbanísticas determinadas como las obligaciones por las disposiciones normativas de los planes y sus reglamentos urbanísticos, a los propietarios de bienes inmuebles, reflejadas en la urbanización de terrenos y en las cesiones urbanísticas gratuitas a los municipios y distritos, para zonas verdes recreativas y equipamientos colectivos. (Ver gráfica Metodología Armonización entre la Ley 388 de 1997 y el Decreto 1729 de 2002; y Metodología Gestión Urbana con visión Participativa y Sostenible). Lo cual, se explicaría de forma sucinta en la etapa preliminar y sintesis del diagnóstico que retroalimenta de forma lineal la etapa de formulación e implementación del Plan de Ordenamiento en la etapa que se debe consolidad con la visión de la nueva generación en el reconocimiento de los instrumentos de planificación y de gestión vistos en los Pot's, Pd y Pomcas entre otros.

A continuación se determina algunas herramientas de planificación que dentro de la ley 388 de 1997, se han venido implementando en las distintas escalas territoriales las cuales deberán estar determinadas a partir del Sistemas Estructurantes y Secundarios; que corresponde a los sistemas de espacio público primario, tales como vías nacionales, departamentales o locales arteriales y las redes maestras 
de servicios públicas, los cuales son competencias de ejecución por parte de los respectivos entes administrativos a nivel nacional, departamental y municipal. El referente de los sistemas secundarios, corresponde al conjunto de espacios públicos e infraestructura que de acuerdo a lo planificado por el plan, complementan los Sistemas Estructurantes a escala zonal y corresponde a los urbanizadores o promotores ejecutarlos, los Sistemas Secundarios se pueden clasificar en los planes viales, los espacios públicos locales, los zonales de servicios públicos y los sistemas de equipamiento zonales. En el año 2007 el Decreto 3600 establece la Unidad de Actuación, como el soporte básico del Plan el cual garantiza que el desarrollo se dé en forma ordenada y los terrenos queden equipados adecuadamente bien sea su participación pública y privada, la Unidad de Actuación no debe ser inferior a 15 hectáreas para ciudades de 100.000 habitantes y a 10 hectáreas en las menores, para garantizar áreas libres suficientes ye $\mathrm{n}$ proporciones adecuadas y terrenos aptos para desarrollar los nuevos equipamientos colectivos.

Algunas actuaciones en Unidades se pueden desde la base urbanística, el cual consiste en la ejecución de actuaciones urbanísticas mediante Unidades de Actuación y su delimitación se suscribe espacialmente en el ámbito jurídico de una Unidad de Actuación, para aplicar los instrumentos de gestión urbana y financiera lo que permitirán ejecutar la planeación definida en un plan de ordenamiento de una manera equitativa, rentable y con elementos urbanísticos y arquitectónicos acordes con el ordenamiento del territorio definidos en el Plan de Ordenamiento y fortalecido a través de los Planes de Desarrollo y de los Pomcas. La definición de desarrollo prioritario para Unidades de Actuación Urbanística, corresponde a la determinación que las actuaciones urbanísticas previstas para ejecutar mediante Unidades de Actuación, se deben realizar con el carácter impositivo y obligatorio, para el efecto, los plazos ordinarios establecidos por la Ley 388 de 1997, se incrementaran en un $50 \%$ en caso de incumplimiento la enajenación forzosa se realizará para la totalidad de inmuebles que conforman la Unidad de Actuación Urbanística.

Para cada establecimiento de Unidad de Actuación se analizarán en profundidad, a partir de la lectura y respeto de los niveles de prevalencia, cada uno de los sistemas zonales o locales, para establecer su situación actual e iniciar la aproximación a propuestas por cada una de ellas, de lo que serán los sistemas secundarios de la siguiente manera.

- Plan vial zonal o local.

- El sistema local o zonal de espacios públicos locales tanto en sus elementos constitutivos naturales, como artificiales o construidos los cuales se pueden espacializar a través de la Estructura Ecológica Principal EEP.

- Los principales equipamientos urbanos zonales o rurales y sus posibles sistemas o subsistemas.

- La situación en materia de cada una de las redes secundarias de los servicios públicos, cobertura, calidad del servicio, deficiencias y dificultades técnicas para superarlas. 
Todo lo anterior, se debe planificar y ordenar respetando los niveles de prevalencia con respecto al Plan de Ordenamiento Territorial y por supuesto al Plan de Manejo Integral de Cuencas Hidrográficas (Pomca), considerado de mayor jerarquía en el ordenamiento del territorio.

Incorporación de los Comités de Integración Territorial (CIT) al fortalecimiento de las Unidades de Planificación.

A partir de elementos, conceptos anteriormente determinados y soportados normativamente en el año 2000 se da a conocer la ley 614 del 18 de septiembre, promulgado por la administración del gobierno del Presidente Andrés Pastrana, dicha ley, fortaleció en términos de integración territorial municipal a través de las directrices promulgadas desde la ley 388 de 1997, la cual fijó los parámetros para los Planes de Ordenamiento Territorial Municipal para todo el territorio nacional de Colombia. La Ley 614 Permitiendo la conformación de los Comités de Integración Territorial (Cit), cuyo fin permite la conformación de cuerpos colegiados en los cuales las autoridades competentes concertarán los referente a la implementación de los planes de ordenamiento territorial y a la presentación de la visión estratégica de desarrollo futuro del área de influencia territorial, lo cual se propicia como el mejor escenario de participación comunitaria, en asocio con sectores y grupos decisión.

Algunos valores agregados de los Comités de Integración Territorial, es la recopilación de la información necesaria para el objeto de desarrollo en el territorio conformado, proveniente de cualquier institución pública o privada, también promoverán la creación de los sistemas de información geográfica integrada al área de influencia.

El área de influencia se entiende el conformado por la capital de departamento o municipio principal y municipios circunvecinos, en los cuales se presenten hechos que hagan indispensable la implementación conjunta de los planes de ordenamiento territorial y planes de desarrollo, tales como los fenómenos de conurbación, relaciones estrechas en el uso del suelo o relaciones estrechas en la prestación de servicios públicos. El área de influencia se deberá hacer en consenso entre los municipios que cumplan con las características para su conformación.

Por lo tanto, las bases propositivas de ordenamiento territorial de la Ley 388 de 1997, ha venido complementándose al tercer año de haberse promulgado la ley, se complementa con la creación de los Comités de Integración Territorial (Cit), los cuales permitirán para la adopción de los planes de ordenamiento territorial y planes de desarrollo, tener los mecanismos de integración, armonización e implementación de las diferentes entidades competentes en materia de ordenamiento del territorio, además de posibilitar la armonización territorial. Así mismo los Cit, son cuerpos colegiados en los cuales las autoridades competentes concertarán la presentación de la visión estratégica de desarrollo futuro del área de influencia territorial; así mismo serán los escenarios propicios para el fortalecimiento de la participación comunitaria, en ejercicio de las diferentes actividades urbanísticas. Por lo tanto, los mecanismos de integración e implementación de los comités de integración territorial, serán armonizados a través de las distintas figuras de unidades de 
planificación y de gestión territorial anteriormente expuestas. Lo cual, permiten entender el área de influencia conformado por la capital de departamento o municipio principal y municipios circunvecinos, en los cuales se presenten hechos que hagan indispensable la implementación conjunta de los planes de ordenamiento y en desarrollo de los planes de desarrollo. La definición del área de influencia deberá ser en consenso entre los municipios que cumplan con las características para su conformación.

Seguidamente, se presenta en la secuencia de figuras el planteamiento de la Cit para construcción del cumplimiento de la integración territorial a través de la complementariedad de la Estructura Ecológica Principal, teniendo en cuenta la división político administrativa vigente de los municipios, posteriormente, se puede establecer bajo criterios de los Planes de Ordenamiento Territorial el régimen de capacidad de uso y manejo de tierras teniendo en cuenta las características establecidas por el Instituto Geográfico Agustín Codazzi (Igac) y soportados técnicamente desde el aporte de los Planes de Manejo de Ordenamiento de Cuencas Hidrográficas.

Mapa 1: Espacialización e integración territorial a través de la armonización de la entidad municipal.

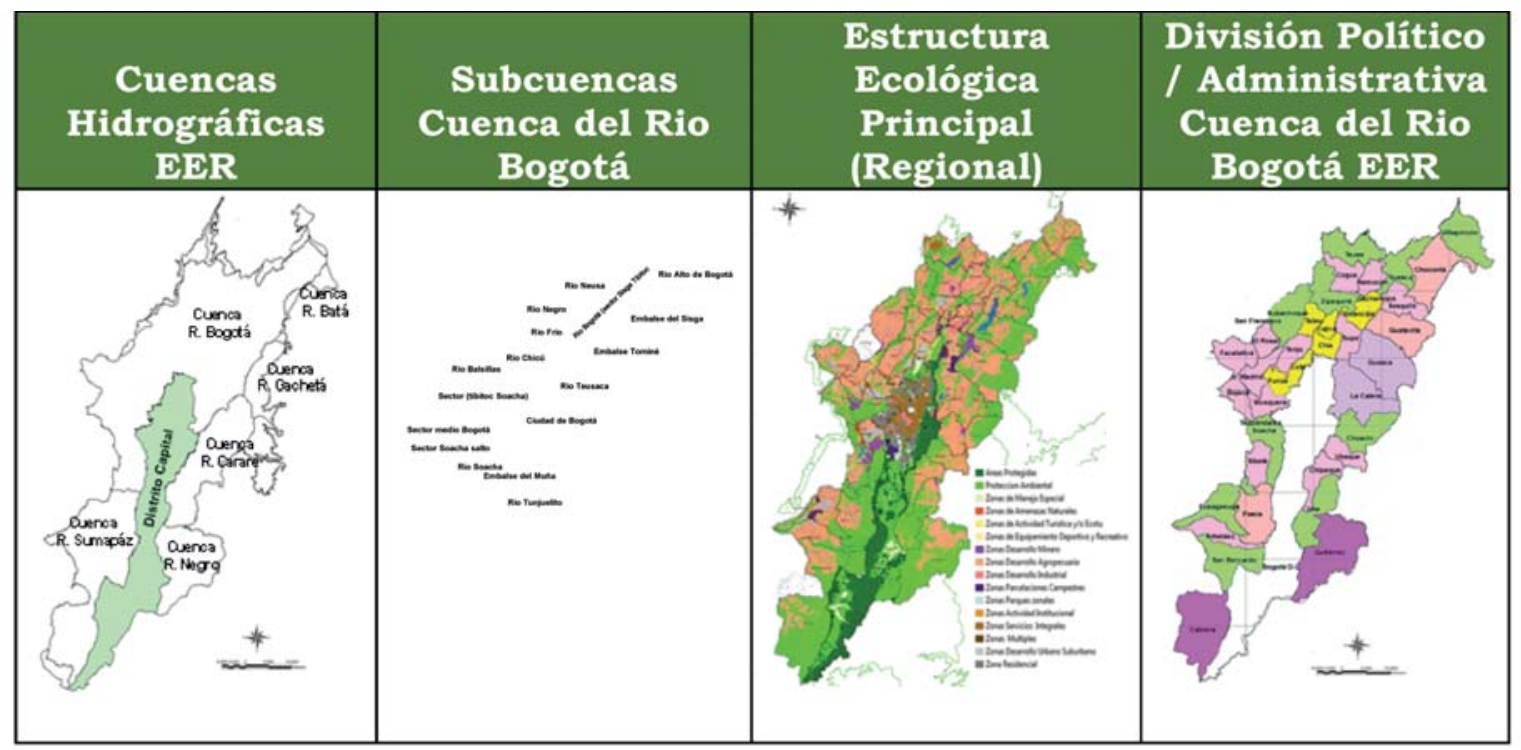

Fuente: Elaborado por el autor. Trabajo de tesis de Magister Ernesto Villegas Rodríguez registrado en la base SEDICI - UNLP DE Argentina. Propuesta de lineamientos conceptuales y metodológicos para la planificación de la gestión sostenible de la cuenca hidrográfica del río Bogotá, desde una perspectiva regional.

Estructura Ecológica Principal. (EEP) como elemento de ordenación y de planificación de la Unidades de Planificación.

Para el ordenamiento y la gestión territorial Colombia ha venido impulsando la incorporación de la e han acogido dos definiciones de la EEP, la primera a través 
de la promulgación de la Ley 1450 por la cual se aprueba el Plan Nacional de Desarrollo Pnd 2010 - 2014, "Prosperidad para Todos", en su Capítulo VI, recalca la importancia de la identificación de la Dimensión Ambiental en el ordenamiento territorial, Ley 388 de 1997). Además señala la identificación y la caracterización de los servicios ecosistémicos y la definición de la Estructura Ecológica Principal, para su incorporación en los planes e instrumentos de planificación tanto en lo sectorial y territorial, de acuerdo con el Pnd la Eep se entiende como "El conjunto de ecosistemas estratégicos que garantizan la integralidad de la biodiversidad y la provisión de servicios ecosistémicos con el fin de satisfacer las necesidades básicas de la población”.

Respaldo de la visión del marco institucional para la zonificación de las unidades de planificación desde lo urbano-rural.

A continuación se presenta el resultado de un sinnúmero de probabilidades territoriales de administración territorial a través de las Unidades de Gestión para poder definir el modelo más conveniente de asociación territorial, a una escala intermedia entre lo urbano y rural en un municipio característico de nuestra conformación político-administrativa con base en las Unidades de Gestión y de Planificación Territorial identificadas desde un conocimiento amplio y decisorio en la ocupación y desarrollo territorial, donde se involucran distintas variables para su caracterización como la social, económica y ambiental, se determina un territorio específico que por sus condiciones de localización hacen de ella un territorio estratégico en la evaluación a articulación de los distintos instrumentos de planificación, cuyas condiciones hoy en día garanticen el mejoramiento del desempeño fiscal por ejemplo.

Para el caso del modelo de Gestión Territorial se debe tener en cuenta la influencia directa de los centros poblados mayores que puedan jalonar el crecimiento territorial hacia la conformación regional convirtiendo al municipio con mayor fortaleza en su desempeño administrativo fiscal y financiero, que garantice a corto plazo su sostenibilidad territorial, según lo evaluado en el año 2011/12/13/ de desempeño fiscal proporcionado por el Departamento Nacional de Planeación (DNP, Resultados del desempeño fiscal de los departamentos y municipios de la vigencia 2012, Departamento Nacional de Planeación, Colombia 2012 ) lo cual determina la posibilidad que el municipio se pueda recategorizar ganando beneficios para la planeación y gestión territorial estructurados en las inversiones en los Planes de Desarrollo y consolidados en los Pot's y los Pomcas.

Por lo tanto, el objetivo de intervenir el territorio es el de fundamentar el uso de la Planificación y la Gestión Territorio, el cual debe ser la de corregir los desequilibrios territoriales con el objetivo de mejorar la calidad de vida, armonizar la utilización de los recursos naturales con la protección conservación, preservación y restauración ambiental teniendo en cuenta los procesos de adaptabilidad y resiliencia hacia la disminución de los impactos del cambio y calentamiento global para los centros urbanos que han llegado a crecimiento y concentraciones poblacional que superen su capacidad en su propia administración, la capacidad de determinar los servicios 
básicos entre otros. Para ello, la búsqueda de experiencias y conocimientos en la implementación de Unidades de Gestión y de Planificación estará enmarcado en el reconocimiento de experiencias locales e internacionales hasta la caracterización de los avances locales que se han venido dando como es el caso colombiano.

El proyecto de investigación determinó una gran probabilidad de organizaciones en el territorio teniendo en cuenta visiones que involucra aspectos sociales, económicos, ambientales y culturales que administrativamente se determinan desde la visión espacial como composición en la armonización territorial. Para ello, se dio el resultado del apoyo conceptual para dicho fortalecimiento en el caso que se llegase a establecer la organización y administración del territorio. A continuación se presenta el marco referencial de Unidades adaptadas a las determinaciones para su espacialización, primero teniendo las características de los desde los denominados niveles de prevalencia establecidos como herramientas de planificación territorial de la Ley 388 de 1997.

\section{Zonificación urbano regional desde los Niveles de Prevalencia.}

Para llegar a la determinación de Unidades de Planificación y de gestión territorial y poder determinar la zonificación del territorio tanto en el contexto urbano como rural, se pueden establecer los denominados niveles de prevalencia, reconocidos por la Ley 388 de 1997. Lo cual es determinante para identificar los niveles de subordinación con los distintos instrumentos de planificación, (Planes de Desarrollo - Planes de Ordenamiento Territorial - Planes de Manejo y Ordenamiento de Cuencas Hidrográficas entre otros). Por lo tanto, considerados los niveles de prevalencia como valores de jerarquía que determinan la subordinación que debe existir entre las determinaciones de los diferentes instrumentos de planificación y de gestión del ordenamiento físico, en los cuales se clasifican los suelos, sus usos, tratamientos urbanísticos e índices urbanísticos; se determinan a partir de los siguientes niveles de prevalencia con el fin de jerarquizar los niveles de relación territorial o vínculos espaciales. 
Mapa 2: Espacialización para la armonización e integración territorial desde la visión de Unidades de Gestión.

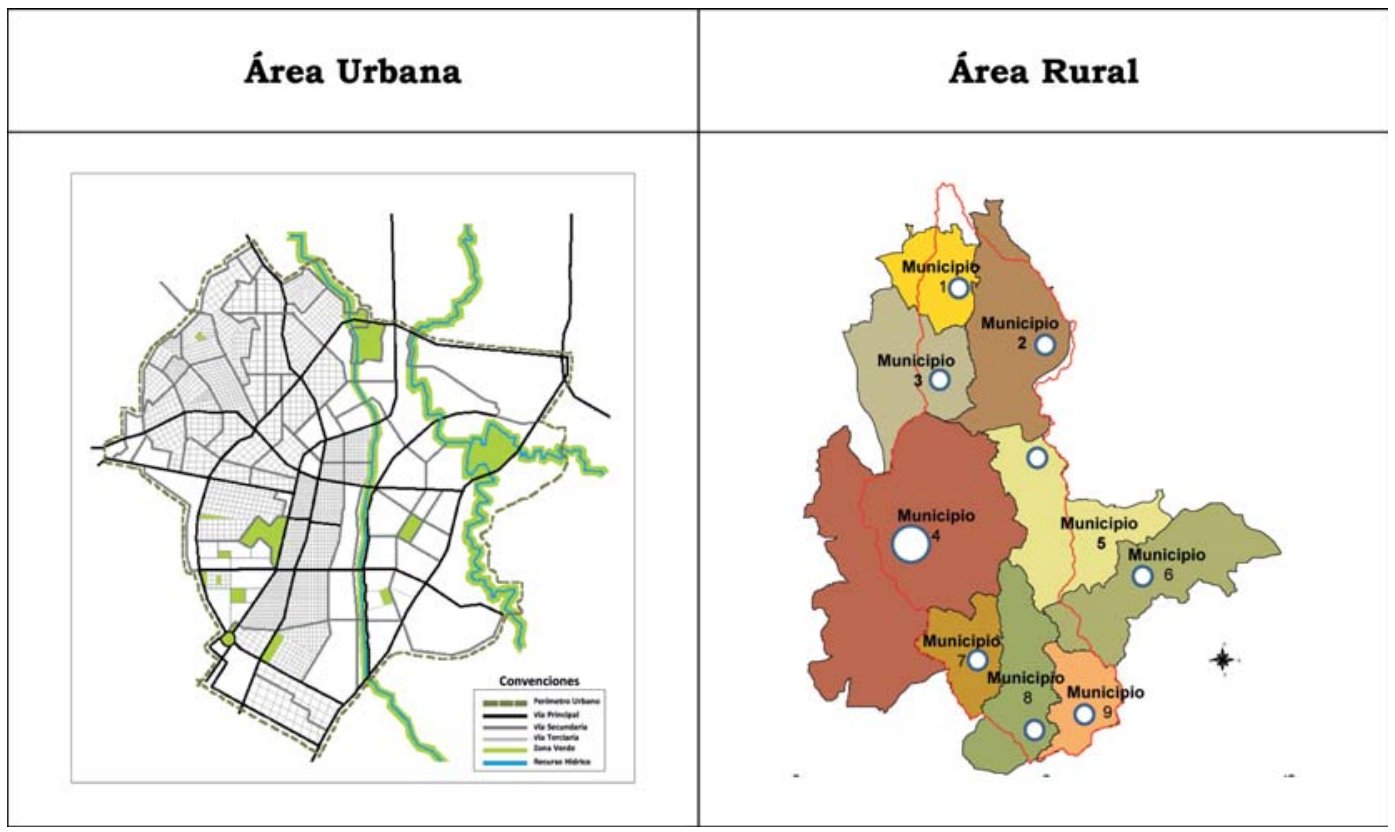

Fuente: Elaboración propia.

\section{Conclusiones.}

Para la modificación y ajuste de los Planes de Ordenamiento Territorial de las ciudades y municipios en Colombia, debe tenerse en cuenta lo establecido en los instrumentos de planificación especialmente en el Decreto 3600 de 2007.

Por lo tanto, la armonización de las áreas para la producción agrícola y ganadera y de explotación de recursos naturales se deben tener en cuenta desde la visión de la zonificación ambiental planteada desde la dimensión ambiental del territorio, lo cual conlleva, a procesos de concertación entre los distintos sectores público, privado y sociedad civil, persistentemente teniendo las divisiones administrativas como condición de negociación.

Las determinantes, seguidamente identificadas es la estructura que coadyuva a relacionar las distintas instancias administrativas para llevar la aplicabilidad de los distintos instrumentos de planificación entre ellos, el Plan Nacional de Desarrollo, Planes departamentales y municipales desde la aplicabilidad de la Ley 152 de 1994; además, el Plan de Ordenamiento Territorial del municipio Ley 388 de 1997 y Decreto 3600 de 2007; en términos ambientales y territoriales los Planes de Manejo Integral de Cuencas Hidrográficas respaldados por los Decretos 1729 de 2002 y 1640 de 2012 que complementan entre ellos, los procesos a seguir en los planteamientos de planificación y ordenamiento territorial las etapas metodológicas e identificación de instrumentos de armonización de políticas públicas que ayuden en cada uno de los espacios de las siete determinantes a la identificación de 
programas y proyectos comunes que fortalezcan las decisiones en conjunto con el fin de que las inversiones se realicen de una forma mucho más colectiva.

- Las determinantes del nivel nacional.

- Las determinantes del nivel departamental.

- Las determinantes del nivel metropolitano.

- Las determinantes del componente general del Plan de Ordenamiento Territorial.

- Las determinantes del componente urbano o rural del Plan de Ordenamiento Territorial.

- Las determinantes de los Planes Parciales.

- Las determinantes que rigen Unidades de Actuación Urbanística.

En términos generales lo que llevó al análisis de las Unidad de Planificación Territorial y de Gestión, como instrumento operativo para la toma de decisiones urbano rural en los POT y PDM en la investigación, y traída en este artículo. Es la gran variabilidad de conceptos de Unidades que se han venido promulgando a los largo de las dos últimas décadas, tanto a nivel internacional como nacional y su intervención o énfasis en los temas ambientales, sociales, económicos, administrativos en fin en términos territoriales, comprometiendo a la organización territorial como resultado de la descentralización municipal, en la jurisdicción de la aplicación de los mecanismos de articulación de gestión territorial con una visión mucho regional, lo cual como se ha venido trabajando en la administración y la gestión territorial dificultan la interrelación con los diferentes niveles de la organización territorial y de planeación existente.

Por lo tanto, los resultados del análisis de las Unidad de Planificación, como instrumento operativo para la toma de decisiones urbano rural en los Pot, Pdm y Pomcas además de proporcionar la armonización de los diferentes instrumentos gestión, los cuales los hemos reconocido a través de la promulgación de políticas públicas que contribuyen a garantizar la ejecución de los programas y proyectos identificados Pot, Pdm y Pomcas, teniendo en cuenta la perspectiva regional a partir de incluir la Unidad de Gestión y de Planificación Territorial (Ugpt), como la propuesta viable en las tomas de decisión desde el sector público, donde sector privado y sociedad civil se convierten en aliados estratégicos en el desarrollo y crecimiento territorial.

Para que la armonización de los Planes de Desarrollo y los Planes de Ordenamiento Territorial, se den de tal manera, se debe contar con una fase de armonización y planteamiento del proceso de territorialización en el tiempo donde se establezcan claramente los recursos humanos y técnicos para la armonización que permitan hacer de la Unidad de Gestión y de Planificación Territorial (Ugpt) como el instrumento viable en la gestión y planificación hacia el fortalecimiento regional administrativamente.

Hoy en día la discusión se ha venido consolidando en entender que dinámicas como lo ambiental, lo social, lo económico, lo cultural, lo institucional y lo territorial visto entre las relaciones urbanas rurales, acompañan decisiones en politicas 
públicas y estas relacionarlas con el ordenamiento territorial; enmarcando nuevas discusiones y nuevas visiones de relaciones al ordenamiento jurídico territorial del país, dinámicas más acordes con visiones globales de interconexión y negociación económicas y ambientales entre los distintos territorios.

Con el fin de alcanzar lo anterior, el artículo implica un nuevo enfoque en la concepción de la planificación urbana y rural hacia el desarrollo regional, introduciendo la dimensión ambiental en la interpretación de las políticas públicas, mediante el desarrollo económico y social que debe ser compatible con la conservación, preservación, protección y recuperación de los recursos naturales que requieren las próximas generaciones para su desarrollo; lo cual constituye el marco general de orientación en los conceptos y lineamentos para el Modelo de Desarrollo Regional, desde la visión de la Unidad de Planificación de Gestión y Territorial (Ugpt), como instrumento operativo para la toma de decisiones urbano rural desde los Pot, Pdm y Pomcas.

Finalmente, en términos propositivos, se reconocen algunos instrumentos para la regionalización, teniendo en cuenta la división politico/administrativa y la integralidad de la zonificación ecológica, la estructura Ecológica Principal con el fin de impedir que la Unidad de Gestión propuesta, no constituya un fraccionamiento del territorio sino, por el contrario contribuya efectivamente a la integración y articulación político administrativa y a la recomposición del sistemas y redes sociales, económicas, administrativas y ambientales. Por lo tanto, se debe buscar su relación o articulación con las instancias administrativas vigentes tanto en el contexto urbano y rural. 


\section{Referencias Bibliográficas.}

Cdim. (2010). Concepto: unidades agricolas familiares y parcelacionesus. POT. Recuperado el 30 de Abril de 2014, de cdim.esap.edu.co: http://cdim.esap. edu.co/BancoMedios / Documentos\%20PDF/unidades_agr\%C3\%ADcolas_ familiares_parcelaciones_vs_pot.pdf

Davoudi, S. (2007). Cohesión Territorial: relación con la planificación territorial y la política regional. En J. Farinós, \& J. Romero, Territorialidad y buen gobierno para el desarrollo sostenible (pág. Capitulo III). Valencia: Universidad de Valencia.

Decreto 1640, Por medio del cual se reglamentan los instrumentos para la planificación, ordenación y manejo de las cuencas hidrográficas y acuiferos, y se dictan otras disposiciones. (Presidencia de la República de Colombia. 2 de Agosto de 2012).

Decreto 1729, Por el cual se reglamenta la parte XIII Titulo 2, Capitulo III del Decreto Ley 2811 de 1974, parcialmente el numeral 12 del Artículo $5^{\circ}$ de la Ley 99 de 1993 y se dictan otras disposiciones" (Presidencia de la República de Colombia. 6 de Agosto de 2002).

Decreto 3600, por el cual se reglamentan las disposiciones de las Leyes 99 de 1993 y 388 de 1997 relativas a las determinantes de ordenamiento del suelo rural y al desarrollo de actuaciones urbanísticas de parcelación y edificación en este tipo de suelo y se adoptan ot (Presidencia de la República 20 de Septiembre de 2007).

Decreto 4161, Por el cual se crea la Unidad Administrativa Especial para la Consolidación Territorial y se determinan sus objetivos, estructura y funciones (Departamento Administrativo de la Funcion Pública. Colombia 03 de Noviembre de 2011).

Dnp. (2012). Resultado del desempeño fiscal de los departamentos y municipios de la vigencia 2012. Bogotá: Departamentos Nacional de Planeacion Colombia.

Dnp. (2012). Resultados del desempeño fiscal de los departamentos y municipios de la vigencia 2012, Departamento Nacional de Planeación, Colombia.

Faustino, J., \& Benegas, L. (14-16 de Octubre de 2008). Seminario Internacional. “Cogestión de cuencas hidrográficas: experiencias y desafios”. Obtenido de biblioteca.catie.ac.cr/:

http: / / biblioteca.catie.ac.cr/comunicacion/Publicaciones/Cuencas / Benegas_ Faustino_cogestion.pdf

Global Water Partership. (2009). Manual para la Gestión Integrada de Recursos Hidricos en Cuencas. Obtenido de gwp.org: http://www.gwp.org/Global/ ToolBox/References / A \% 20Handbook\%20for\%20Integrated $\% 20$ Water\%20 Resources\%20Management\%20in\%20Basins\%20\%28INBO,\%20GWP,\%20 2009\%29\%20SPANISH.pdf 
Ley 1450, Por el cual se expide en Plan Nacional de Desarrollo 2010-2014 (Congreso de la República 16 de Junio de 2011).

Ley 1454, Por la cual se dictan normas orgánicas sobre: Ordenamiento territorial y se modifican otras disposiciones (Congreso de la República de Colombia. 28 de Junio de 2011).

Ley 388, Por la cual se modifica la Ley $9^{a}$ de 1989, y la Ley $3^{a}$ de 1991 y se dictan otras disposiciones. (Congreso de la República de Colombia 158 de Julio de 1997).

Ley 614, por medio de la cual se adiciona la Ley 388 de 1997 y se crean los comités de integración territorial para la adopción de los planes de ordenamiento territorial. (Congreso de la República de Colombia 18 de Septiembre de 2000).

Ley 617, por la cual se reforma parcialmente la ley 136 de 1994, el decreto extraordinario 1222 de 1986, se adiciona la ley orgánica de presupuesto, el decreto 1421 de 1993, se dictan otras normas tendientes a fortalecer la descentralización (Congreso de la República de Colombia 6 de Octubre de 2000).

Lopez, B., Serrano Montero, J., \& Martinez, D. A. (2000). Metodología para la definición de Unidades territoriales de gestión como instrumento operativo para la toma de decisiones territoriales. Escuela Superior de Ciencias Experimentales y Tecnologia, 1373-1385.

Nogué, J. (Julio-Diciembre de 2010). El paisaje en el ordenameinto del territorio. la experiencia del Observatorio de Paisaje de Cataluña. Estudios Geográficos, 71(269), 415-468. doi:10.3989/estgeogr.201014

Pochat, V. (2005). Entidades de gestión del agua a nivel de cuencas: experiencias de Argentina. Buenos Aires: Cepal.

Shum, A. (2010). Manual de operaciones de la Unidad de Gestión Ambiental deal Fglcfn. Nicaragua: Fundecor.

Villegas Rodriguez, E. (20 de Noviembre de 2014). Propuestade lineamientos conceptuales y metodológicos para la planificación de la gestión sostenible de la cuenca hidrográfica del Rio Bogotá, desde una perspectiva Regional. Obtenido de Sedici: http://sedici.unlp.edu.ar/handle/10915/42859 